\title{
Osteo-Morphological Studies on the Thoracic Verte- brae of Indian Blackbuck (Antelope cervicapra)
}

\section{Om Prakash Choudhary, Ishwer Singh, Balwinder Singh, Sanjay Kumar Bharti, Khan IdreesMohd, Srinivas Sathapathy and Nishant Kumar}

Department of Veterinary Anatomy, College of Veterinary and Animal Science,

G.B. Pant University of Agriculture and Technology, Pantnagar-263 145 Udham Singh Nagar (Uttrakhand), INDIA

\section{Abstract}

The present study had been carried out on the thoracic vertebrae of blackbuck. There were thirteen thoracic vertebrae, which were characterized by long spinous process, cylindrical but shorter body and presence of cranial and caudal costal facets on their bodies. The supra spinous processes of the thoracic vertebrae increas-ed in length and breadth up to the fourth vertebra $\left(T_{4}\right)$ then gradually decreased. The maximum height of $T_{4}$ was $9.84 \pm 0.028 \mathrm{~cm}$. The backward inclination in the spinous process of thoracic ver-tebrae increased up to the ninth and then decreased. The greatest length of thoracic vertebrae $\left(T_{1}\right.$ to $\left.T_{13}\right)$ was $30.56 \pm$ $0.115 \mathrm{~cm}$ in blackbuck.

Keywords: Blackbuck, thoracic, vertebrae, spinous process, transverse process.

\section{Introduction}

The blackbuck (Antilope cervicapra) is an ungulate species of antelope native to the Indian Subcontinent that has been classified as near threatened by IUCN since 2003. The blackbuck is protected under Schedule I of the Indian Wildlife Protection Act, 1972. The aim of this study is to investigate the thoracic vertebrae of blackbuck, thereby making a contribution in filling the gap of knowledge in this field. As per knowledge, in many vetero legal cases one fails to identify the bones of this animal and confuse them with those of some other small ruminants. This investigation will be helpful to the field veterinarians as well as zoo veterinarians.

\section{Material and Methods}

The present study was conducted on the thoracic vertebrae of six adult blackbuck of either sex. The permis- 
sion for the specimen collection was sought from the Deputy Inspector General (WL), Ministry of Environment and Forests (MoEF), New Delhi, India and Principal Chief Conservator of Forest (PCCF), Government of Rajasthan. The skeletons were collected from the Jodhpur zoo after official approvals from the Principal Chief Conservator of Forest (PCCF) vide letter no. F, 3(02) Tech-II/CCF/2010/714 dated 07.05.2014. The skeletons were excavated out from the graveyards located in the premises of Jodhpur zoo and processed as per standard technique (Raghavan, 1964). Subsequently, these osteological specimens were studies to record their gross morphological features. Different parameters of the thoracic vertebrae were measured and subjected to routine statistical analysis as described by Snedecor and Cochran, (1994). Nomina Anatomica Veterinaria (2005) was used in describing the anatomical features in the study.

\section{Results and discussion}

In the present study there were thirteen thoracic vertebrae charac-terized by long spinous process (Fig. $1 \& 2$ ), cylindrical but shorter body and presence of cranial and caudal costal facets on the bodies. These findings were in corroboration to the observations made by Raghavan (1964) in ox, Miller et al. (1964) in dog, Maala et al. (1992) in cala-mian deer, Kumar et al. (2000) in red deer and Meena et al. (2013) in chital. In contrast, Getty

J. Vet. Anat.
(1975) reported eighteen thoracic vertebrae in horse. According to Smuts and Bezuidenhout, (1987) there were twelve thoracic vertebrae in camel. Yilmaz (1998) reported that there are fifteen in porcupine and also, according to Yilmaz et al. (2000), fourteen thoracic vertebrae are present in otters.

The spinous processes of thoracic vertebrae increased in length and breadth up to the fourth vertebra and then gradually decreased in blackbuck, which was in conformity with the observations of Getty (1975) in horse, Maala et al. (1992) in calamian deer and Meena et al. (2000) in chital. Kumar et al. (2000) and Meena et al. (2013) recorded the height of $\mathrm{T}_{4}$ in red deer and chital to be $10.39 \pm 0.269$ and $14.28 \pm 0.09 \mathrm{~cm}$ (maximum) respectively, but in blackbuck it was $9.84 \pm 0.028 \mathrm{~cm}$. In fourth thoracic vertebra as recorded in this study revealing a shorter spine in blackbuck than in red deer and chital. Whereas, the second or third thoracic vertebra was the highest in ox (Raghavan, 1964), fifth or sixth vertebra was the highest in camel (Smuts and Bezuidenhout, 1987) and the height decreased from third verte-bra in otters (Yilmaz et al., 2000).

The backward inclination in the spinous process (Fig.2) of the thora-cic vertebrae increased up to the ninth and then decreased as also reported in horse (Getty, 1975), in ox Vol. 8, No. 1, (2015) 31 - 36 
(Raghavan, 1964), in dog (Miller et al., 1964) and in camel (Smuts and Bezuidenhout, 1987). In contrast, the first eleven were caudally sloped in porcupine (Yilmaz, 1998) and the first ten were caudally sloped in otters (Yilmaz et al., 2000).

The spine, presented two sur-faces two borders and a summit. The lateral surfaces were convex and the borders were nearly straight while the summit was thick and tuberous. These findings were more or less similar to that in horse (Getty, 1975), in camel (Smuts and Bezuidenhout, 1987) and in Calamian deer (Maala et al., 1992). The summits of the seventh to tenth vertebrae were distinctly bifid in ox (Raghavan, 1964)which was not observed in blackbuck of this study.

The spine of the thirteenth thora-cic vertebra was vertical in blackbuck similar to that reportedin ox (Raghavan, 1964). The spine ofthe eleventh thoracic vertebra was vertical in dog (Miller et al., 1964) and in otters (Yilmaz et al., 2000) and the eleventh and twelfth in camel (Smuts and Bezuidenhout, 1987). The spinous process was in the form of two tubercles in the first two thoracic vertebrae and was formed of a thin median ridge in the remaining ver-tebrae. This finding was con-current to the findings in ox (Raghavan, 1964) but the same was more prominent in camel (Smuts and Bezuidenhout, 1987).
The articular processes in the blackbuck thoracic vertebra were small. The cranial articular proc-esses were oval, slightly convex and were placed on the dorsal border of the arch and directed upwards. The caudal articular processes were placed at the base of the spinous process. They were slightly concave and faced downwards. The cranial articular facets were widely separated in the first thoracic vertebra and were associated with the transverse process (Fig.1) in blackbuck. The same findings were also observed by Getty (1964) in horse, Raghavan (1964) in ox and Smuts and Bezuidenhout (1987) in camel.

The transverse processes were short, thick and single. Each transverse process possessed a tubercular facet on its ventral aspect for articulation with the tubercle of the rib. This facet decreased in size and convexity from the first to the eleventh thoracic vertebra and were absent in the twelfth and thirteenth thoracic ver-tebrae. They possessed thick round-ed mamillary processes on the dorsal aspect that were fused with the cranial articular processes in the twelfth and thirteenth thoracic vertebrae. This was in accordance with the findings of Raghavan (1964) in ox, Miller et al. (1964) in dog and Smuts and Bezuidenhout (1987) in camel. According to Kumar et al. (2000), the transverse process lengths (TPL) were fairly uniform in the thoracic spine. 
The minimum TPL was $1.10 \pm 0.082$ $\mathrm{cm}$ at twelfth thoracic vertebra in red deer. Meena et al. (2013) also stated in chital that TPL min was $1.6 \pm 0.06$ $\mathrm{cm}$ at eleventh and twelfth thoracic vertebra but transverse process lengths (TPL) were not uniform in the thoracic spine of the blackbuck and $\mathrm{TPL}_{\max }$ was $1.96 \pm 0.009 \mathrm{~cm}$ at $\mathrm{T}_{4}$ and $\mathrm{T}_{5}$ vertebraand $\mathrm{TPL}_{\min }$ was $0.96 \pm$ $0.010 \mathrm{~cm}$ found at $T_{11}$ and $T_{12}$ vertebra. The greatest length of thoracic vertebrae ( $T_{1}$ to $\left.T_{13}\right)$ was 30.56 $0.115 \mathrm{~cm}$ in blackbuck.

\section{Conclusion}

There were thirteen thoracic vertebrae that were characterized by long spinous processes, cylindrical but shorter bodies and presence of cranial and caudal costal facets on their bodies. The spinous processes of the thoracic vertebrae increased in length and breadth up to the fourth vertebra $\left(T_{4}\right)$ then gradually decreased.

\section{Acknowledgement}

The authors are thankful to the Deputy Inspector General, Ministry of Environment of Forests (MoEF), New Delhi and Jodhpur Zoo for providing facilities and financial backing for carrying out research on the bones of Indian blackbuck. Financial support was provided by the Department of Science and Technology, New Delhi, India as Ph.D. grant (DST-INSPIRE Fellowship) to the first author.

\section{References}

Getty, R. Sisson and Grossman's. (1975): The Anatomy of the Domestic Animals. Vol. I, $5^{\text {th }}$ ed. W.B. Saunders Company, Philadelphia.

Kumar, N., Kukreti, S., Ishaque, M. and Mulholland, R. (2000): Anatomy of deer spine and its comparison to the human spine. The Anatomical Record Part A: Discoveries in Molecular, Cellular, and Evolutionary Biology. 260 (4): 189-203.

Maala, C.P., Arca, R.R., Bravo, M.V.A., Villamor, C. and Marte, R.G. (1992): Vertebral column of the calamian deer (Cervus calamia-nensis) axis. Philippine Journal of Veterinary and Animal Sciences. 18: 229-238.

Meena, V., Mathur, R., Joshi, S. and Choudhary, O.P. (2013): Gross Studies on the Thoracic and Lumbar Vertebrae in Chital (Axis axis). Indian Journal of Veterinary Anatomy. 25(2): 83-85.

Miller, M.E., Christensen, G.C. and Evans, H.E. (1964): Anatomy of the Dog. W.B. Saunders Company, Philadelphia.

NAV (2005): Nomina Anatomica Veterinaria, International Committee on Veterinary Gross Anatomical Nomenclature. $5^{\text {th }}$ Ed. Pub. By the Ed. Com. Hannover, Columbia, Gent, Supparo, USA. 
Raghavan, D. (1964): Anatomy of ox. Indian Council of Agricultural Research, New Delhi, 1964.

Smuts, M. and Bezuidenhout, A.J. (1987): Anatomy of the Dromedary. Clarendon Press, Oxford, UK.

Snedecor, G.W. and Cochran, W.G. (1994): Statistical Methods. $8^{\text {th }}$ ed. Iowa State University Press, Ames, Iowa, USA.

Yilmaz, S., Dinç, G. and Toprak, B. (2000): Macro-anatomical investigations on skeletons of otter (Lutra lutra). III. Skeleton axiale. VeterinarskiArhiv. 70: 191-198.
Yilmaz, S. (1998): Macro-Anatomical investigations on the skeletons of porcupine (Hystrixcristita). Anatomia Histologia Embryoligia. 27: 293-296.

\section{Correspondence address: \\ Dr. Ishwer Singh, Professor and Head, Department of Veterinary Anatomy, Col- lege of Veterinary and Animal Science, G.B. Pant University of Agriculture and Technology, Pantnagar-263 145, INDIA Email: singh iswar@yahoo.com}




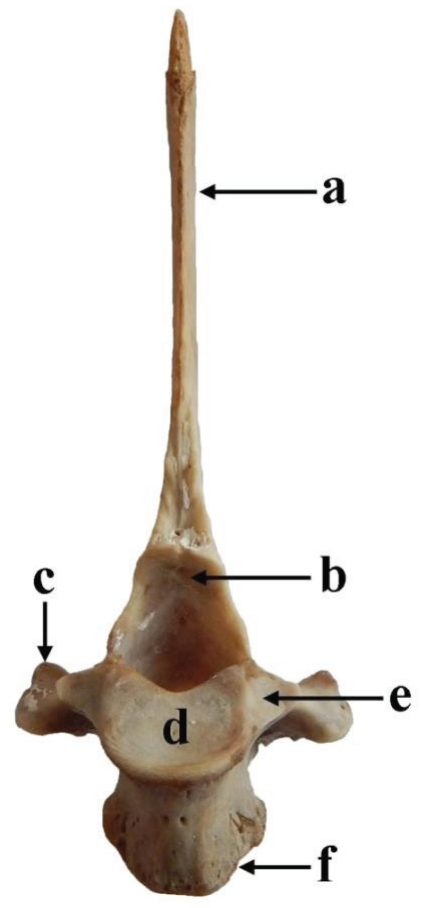

Fig (1): Caudal view of thoracic vertebra in blackbuck showing: spinous process (a), articular surface (b), transverse process (c), caudal articular area (d), articular facet (e), cranial articular area (f).

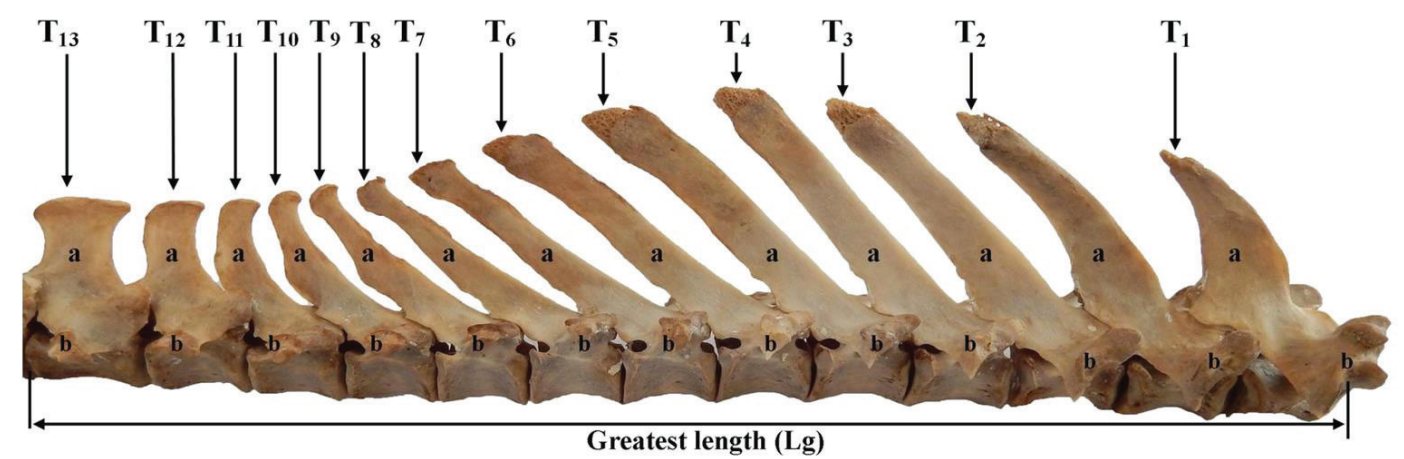

Fig (2): Lateral view ofthoracic vertebrae $\left(T_{1}-T_{13}\right)$ of blackbuck showing: spinous process (a), tubercular facet (b), greatest length ( $\mathrm{Lg})$. 